\title{
Parte V
}

\section{Seminários Kadila}

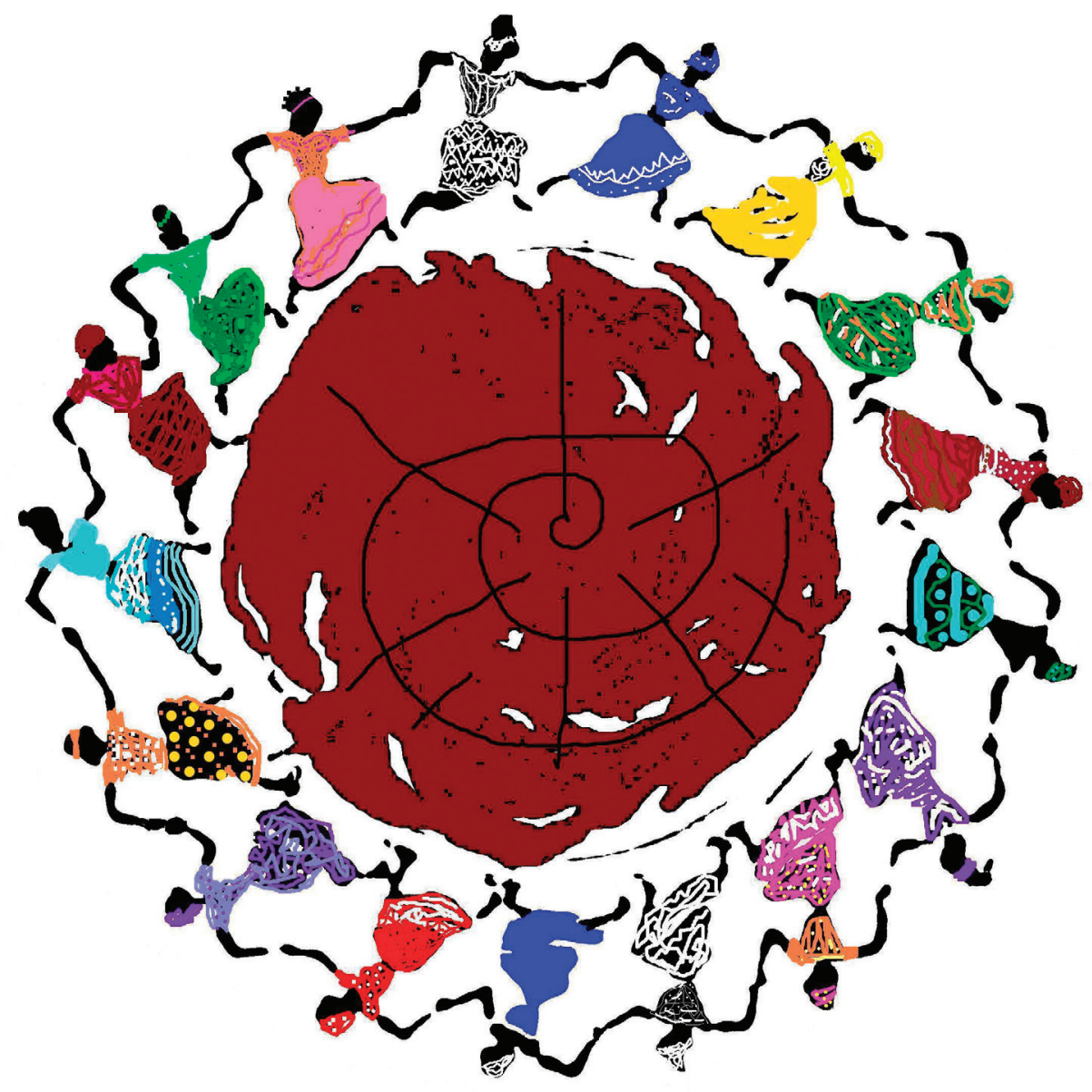




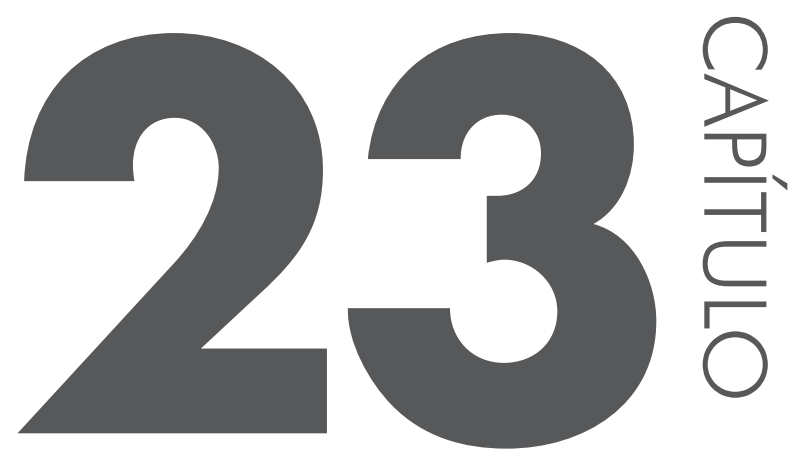

\section{Apresentação dos seminários Kadila}

\section{Letícia Cesarino}

Universidade Federal de Santa Catarina

Os seminários do Projeto Kadila iniciaram-se em 2012 como estratégia de implantação do projeto entre os dois centros de pesquisa, o NUER e o CE.DO. Seguiram um cronograma de acordo com os ciclos de seu desenvolvimento, as missões de trabalho realizadas nos dois países e, sobretudo, nos dois primeiros anos de vigência da primeira etapa do edital CAPES/AULP, entre 2013-2015. Os seminários tiveram como objetivo principal ativar os encontros e diálogos entre os pesquisadores e os centros de pesquisa, ampliando também para a participação da comunidade universitária, o que possibilitou, assim, uma disseminação das discussões, das temáticas e teorias para um público mais diversificado.

Contamos ao longo do projeto com seis seminários, arrolados a seguir:

- I Seminário: Apresentação do Observatório da Transumância na UFSC setembro de 2012.

- II Seminário: Primeira Oficina de trabalho do Projeto do Observatório da Transumância - UAN, Luanda, fevereiro de 2013.

- III Seminário: Reunião de Planejamento das Missões de trabalho e Pesquisa - NUER/UFSC, Florianópolis, março de 2013.

- IV Seminário: Encontro Programa CAPES-AULP com Estudantes Africanos - NUER/UFSC, fevereiro de 2014.

- V Seminário: Segunda Oficina do Observatório da Transumância CE.DO e NUER - Luanda, UAN, março de 2014. 
- VI Seminário: Projeto Kadila: africanias, diásporas e transumâncias apresentação de pesquisas. Coordenado por Leticia Cesarino - UFSC, 2015.

O VI Seminário foi concebido durante o segundo ano e constitui um braço de extensão do projeto Kadila: culturas e ambientes, através da participação de pesquisadores e acadêmicos trabalhando com/em África, e questões africanas de dentro e fora da UFSC.

Consideramos importante promover encontros para compartilhar nossos interesses e trabalhos e para promover debates em torno de questões teóricas e empíricas de interesse do projeto. Tratou-se, também, de um fórum para divulgação e para debate dos resultados do projeto nas duas universidades. No ano de 2015, o VI Seminário realizou nove palestras, dos quais cinco resultaram em textos ou súmulas incluídas no presente volume.

O primeiro convidado, Joaquim Nhampoca, pesquisador da Universidade Eduardo Mondlane, de passagem pela UFSC, nos falou sobre a ideia de África numa perspectiva filosófica e conceitual, para lançar algumas questões críticas, buscando identificar e desconstruir alguns estereótipos em uso na atualidade. A segunda convidada, Jess Auerbach, antropóloga doutoranda na Universidade de Stanford, compartilhou os resultados de sua pesquisa etnográfica em andamento sobre a constituição das novas classes médias angolanas em sua relação com o Brasil, atentando especialmente para a questão dos perfumes e cheiros como estratégias de demarcação e mobilidade social. O professor Alejandro Labale (UFPI) palestrou sobre seu trabalho com mapeamento de territórios quilombolas no estado de Santa Catarina, fazendo referência à questão das fronteiras econômicas e da territorialidade negra e as áreas de plantation no Brasil. Thiago Sayão, pós-doutorando em História na UFSC, apresentou sua pesquisa sobre a ocultação do associativismo negro e a Irmandade de Nossa Senhora do Rosário (dos Pretos) na cidade de Laguna (SC), no período pós-Abolição, discutindo sobre o reordenamento dos afrodescendentes e a identificação racial no contexto republicano de luta pela cidadania.

Nas demais sessões de palestras, tivemos a participação dos professores Hyppolite Sogbossi (Antropologia/UFSE) e Leda Martins (Letras/UFMG), que discutiram com os participantes do seminário as suas obras -respectivamente, nos campos da antropologia das populações afro-americanas e africanas (Brasil, Haiti, Cuba, Benin) e da performance, teatro e ritual no contexto afro-brasileiro - bem como as possibilidades de diálogo e tensões entre os estudos africanos e afro-brasileiros na atualidade.

Importante registrar, também, a participação de Milena Argenta no VI Se- 
minário, que realizou a primeira pesquisa de campo no Namibe, contribuição que fundamental para o efetivo aprofundamento das contribuições do NUER para o Observatório da Transumância e cujo trabalho sobre os marcadores étnicos na região do Curoca no Deserto do Namibe, Angola, integra um dos capítulos deste livro. Nas últimas sessões tivemos as palestras dos bolsistas angolanos do projeto Kadila, Teresa Aço e Abel Pedro, estudantes de antropologia da Universidade Agostinho Neto que relataram suas vivências como integrantes do Centro de Estudos do Deserto e sobre os trabalhos de campo que realizaram no deserto do Namibe, no Sudoeste de Angola.

O VII e último Seminário do Projeto Kadila,foi realizado na UFSC em julho de 2015 e teve como principal objetivo a recepção da nova coordenadora do convênio com a UAN, a professora Dra. Amélia Mingas. Nesta oportunidade, fizemos uma homenagem ao professor Samuel Aço, que nos deixou repentinamente e também buscamos recepcionar a missão de bolsistas vindos da UAN que passaram um período no NUER trabalhando diretamente com a equipe do projeto. Neste seminário, foram apresentadas as pesquisas em curso e planejamos a organização deste livro, que, sem dúvida alguma, vem coroar uma etapa importante de sedimentação do intercâmbio científico entre a UFSC e a UAN.

Os seminários aqui apresentados possibilitaram, indubitavelmente, o aprofundamento e a renovação dos saberes sobre diversos temas de interesse do Projeto kadila, mas também objetivaram ampliar os horizontes teóricos e interpretativos e as interlocuções tão necessárias ao desenvolvimento dos campos científicos nos dois países, Brasil e Angola. 
